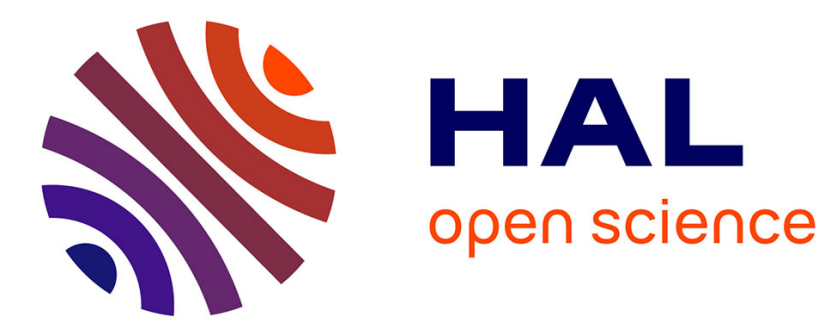

\title{
Thermoelastic Couplings and Interparticle Friction Evidenced by Infrared Thermography in Granular Materials
}

P. Jongchansitto, X. Balandraud, I. Preechawuttipong, Jean-Benoit Le Cam, P. Garnier

\section{To cite this version:}

P. Jongchansitto, X. Balandraud, I. Preechawuttipong, Jean-Benoit Le Cam, P. Garnier. Thermoelastic Couplings and Interparticle Friction Evidenced by Infrared Thermography in Granular Materials. Experimental Mechanics, 2018, 58 (9), pp.1469-1478. 10.1007/s11340-018-0430-3 . hal-01935238

\section{HAL Id: hal-01935238 \\ https://hal-univ-rennes1.archives-ouvertes.fr/hal-01935238}

Submitted on 7 May 2020

HAL is a multi-disciplinary open access archive for the deposit and dissemination of scientific research documents, whether they are published or not. The documents may come from teaching and research institutions in France or abroad, or from public or private research centers.
L'archive ouverte pluridisciplinaire HAL, est destinée au dépôt et à la diffusion de documents scientifiques de niveau recherche, publiés ou non, émanant des établissements d'enseignement et de recherche français ou étrangers, des laboratoires publics ou privés. 


\title{
Thermoelastic Couplings and Interparticle Friction Evidenced by Infrared Thermography in Granular Materials
}

\author{
P. Jongchansitto ${ }^{1}$ (D) $\cdot$ X. Balandraud ${ }^{2} \cdot$ I. Preechawuttipong ${ }^{1} \cdot$ J.-B. Le Cam ${ }^{3} \cdot$ P. Garnier ${ }^{4}$
}

\begin{abstract}
Infrared (IR) thermography was used to analyze the thermomechanical response of a two-dimensional non-cohesive granular assembly. Two constitutive materials with different types of thermoelasticity were chosen: thermoplastic polyurethane (TPU) and polyoxymethylene (POM), which feature entropic and isentropic elasticity respectively. Cylinders of each material were mixed together. Analysis was performed under confined compression at two observation scales. Thermoelastic couplings and interparticle friction were separately evidenced. First, the strong thermal effect of entropic coupling was revealed at the contacts, in the stress concentration zones. Second, image processing enabled us to clearly extract the thermal signature of the interparticle friction zone, a quantity that cannot be identified by the other full-field measurement techniques available today. It can thus be claimed that IR thermography provides two distinct routes for the analysis of granular materials by distinguishing the reversible and irreversible parts from the global thermomechanical response. The study also opens prospects for the experimental analysis of "soft" granular media.
\end{abstract}

Keywords Granular material $\cdot$ Infrared thermography $\cdot$ Thermoelastic coupling $\cdot$ Entropic coupling $\cdot$ Soft material

\section{Introduction}

Granular materials are defined as a collection of solid particles whose macroscopic mechanical behavior is governed by the interaction forces between the particles. They are plentiful around us in our everyday lives (coffee or sugar powders) as well as in many industrial fields, typically sands, soils and rocks in civil engineering; cereal, sugar and rice in the agrofood processing industry; or powders for preparing medical drugs in the pharmaceutical industry. Natural phenomena such as avalanches and landslides are also investigated using granular material mechanics. The mechanical behavior of these

P. Jongchansitto

pawarut.j@cmu.ac.th

1 Department of Mechanical Engineering, Faculty of Engineering, Chiang Mai University, 239 Huay Kaew Rd., Muang District, Chiang Mai 50200, Thailand

2 Université Clermont Auvergne, CNRS, SIGMA Clermont, Institut Pascal, F-63000 Clermont-Ferrand, France

3 Institut de Physique UMR 6251 CNRS/Université de Rennes 1, Campus de Beaulieu, Bât. 10B, 35042 Rennes Cedex, France

4 PCM Technologies S.A.S, Rue René Moineau, 49123 Champtocé-sur-Loire, France materials is very different from that of solids, liquids, and gases $[1,2]$. Granular media generally are composed of grains with different types of constitutive materials and various distributions in terms of size and shape. Pioneering research works were performed by Casagrande and Carillo in 1944 [3], Dantu in 1957 [4], and Rowe in 1962 [5]. Various numerical approaches have been developed to study the influence of parameters such as particle shape, density, polydispersity, particle elasticity, friction, etc. [6]. However, full-field experimental data (captured by camera) remain scarce compared to numerical results. Some techniques are available for measurements in the bulk granular medium: X-ray tomography combined with volumetric digital image correlation [7-9], computerized X-ray tomography [10], flash X-ray shadowgraphy [11], magnetic resonance imaging [12, 13], radar-based sensing [14] and positron emission particle tracking [15]. The carbon paper method has also been used to measure the contact pressures in sections of three-dimensional granular materials [16]. An extensive literature deals with two-dimensional (2D) approaches based on optical photography combined with digital image correlation (DIC), such as in the particle image velocimetry (PIV) technique [17-19]. Concerning the identification of stresses in the particles, photoelasticimetry is a powerful full-field technique which is applicable to $2 \mathrm{D}$ granular media composed of birefringent materials [20-31]. It 
enables for instance the identification of the contact forces by image processing. For the present study, we applied another type of full-field technique, namely full-field temperature measurement by infrared (IR) camera.

For the analysis of thermomechanical behavior, IR thermography is in principle applicable to any type of solid matter. However, its application to granular samples is tricky. The first studies were performed on soils and sands in the framework of vibrothermography [32, 33]. In previous works [34-36], we studied Schneebeli analogue materials [37] through a socalled Thermoelastic Stress Analysis (TSA) [38-40]. However, the amplitudes of the thermal signal were weak due to the use of materials featuring "classical" thermoelastic coupling, which is sometimes named isentropic coupling [41]. The present paper aims to study the thermal response of granular material under confined compression. The constitutive materials of the granular media have two different types of elasticity: isentropic elasticity (such as in metallic materials and polymer materials below their glass transition temperature) and entropic elasticity (such as in rubber-like materials or polymer materials above their glass transition temperature). One of the objectives is to compare isentropic and entropic materials for further use in the experimental thermomechanics of granular media. The aim is to experimentally evidence thermoelastic couplings and self-heating due to interparticle friction with two practical constraints:

- quasi-static loading,

- cyclic loading over a few mechanical cycles.

Indeed, the long-term objective is to be able to perform the analysis of granular systems with only one load-unload mechanical cycle, with any testing machine (not limited to a fatigue machine) or in-situ in a geotechnical context. It is worth noting that TSA is a priori not applicable to the present experiment, for two reasons: first TSA is not currently applicable to entropic materials (see next section); second it is not suitable for quasi-static loading.

The paper is organized as follows: the next two sections presents a brief summary of the two types of thermoelastic couplings, and the experimental set-up; then the "Overall analysis" and "Local analysis" sections are dedicated to analysis at two observation scales, using two different spatial resolutions for the IR thermography measurements.

\section{Background on Thermoelastic Couplings}

Isentropic thermoelastic coupling corresponds to the production or absorption of heat as a function of the variation in internal energy, i.e. the variation in the volumetric part of the strain (first invariant of the strain tensor, also named cubic dilatation). The expression of the heat induced by this thermo-sensitivity can be deduced from the second derivative of the Helmholtz free energy function with respect to temperature and strain. The corresponding heat power density $\mathrm{s}_{\text {isent }}$ can be written as follows for isotropic materials:

$\mathrm{s}_{\text {isent }}=-3 \alpha T \frac{d \sigma_{\mathrm{h}}}{d t}$

where $\alpha$ is the coefficient of thermal expansion, $T$ the absolute temperature in Kelvin, $\sigma_{\mathrm{h}}$ the hydrostatic stress (sum of principal stresses divided by three) and $d \sigma_{\mathrm{h}} / d t$ its temporal derivative. When the hydrostatic stress increases, the material absorbs heat (temperature decrease); when the hydrostatic stress decreases, the material produces heat (temperature increase). Under cyclic loading in adiabatic conditions, the temperature oscillation amplitude $\Delta T$ writes as follows:

$\Delta T=3 \frac{\alpha T_{0}}{\rho C} \Delta \sigma_{\mathrm{h}}$

where $T_{0}$ is the mean temperature in Kelvin, $\rho$ the density, $C$ the specific heat, and $\Delta \sigma_{\mathrm{h}}$ the amplitude of the hydrostatic stress oscillation. Equation (2) is the basis of the TSA approaches. The elasticity of materials featuring this type of thermo-sensitivity is sometimes referred to as energetic, to be distinguished from entropic elasticity [42].

The first studies dealing with entropic coupling date from the nineteenth century, with the pioneering experimental work of Gough [43] and Joule [44]. At the beginning of the twentieth century, Meyer and Ferri proposed to consider rubber elasticity as being driven only by the changes in entropy (ideal elastomer) with an internal energy remaining constant during the deformation process [45]. In this theory, the mechanical work can be entirely measured as a change in the material's temperature. The analytical expression of the heat power density $\mathrm{s}_{\text {ent }}$ due to entropic coupling depends on the deformation state and the model considered for elasticity. For the sake of illustration, let us consider a mechanically incompressible material. The deformation gradient tensor $F$ can be written in the principal basis $\left(e_{1}, e_{2}, e_{3}\right)$ as follows:

$F=\left[\begin{array}{ccc}\lambda & 0 & 0 \\ 0 & \lambda^{B} & 0 \\ 0 & 0 & \lambda^{-(B+1)}\end{array}\right]_{\left(e_{1}, e_{2}, e_{3}\right)}$

where

- $\quad \lambda$ is the stretch in the $e_{1}$ direction, defined as the ratio of the current length to the initial length in the $e_{1}$ direction;

- $\quad B$ is the coefficient of biaxiality [46, 47]. It is equal, for instance, to $-0.5,0$ and 1 for uniaxial tension, pure shear and equibiaxial tension, respectively. 
Let us now consider as an example a Neo-Hookean model for elastic behavior [48]. The heat power density $\mathrm{s}_{\text {ent }}$ due to entropic coupling can be written as follows:

$\mathrm{S}_{\text {ent }}=N k T\left[\lambda+\lambda^{2 B-1}-(B+1) \lambda^{-2 B-3}\right] \frac{d \lambda}{d t}$

where $N$ is the number of network chains per unit volume and $k$ is Boltzmann's constant. It can be noted that entropic materials produce heat when the stretch $\lambda$ increases, and absorb heat when $\lambda$ decreases. Moreover, the link between heat and stretch is non-linear. The calorific response of entropic materials is thus very different from that of isentropic materials.

Equation (4) shows that TSA approaches are not applicable to entropic materials. First, the field of coefficient $B$ is difficult to know a priori in the case of heterogeneous tests. Second, elastomeric materials are actually subjected to significant changes in volume during their deformation [49]. Equation (4) is thus valid only for a Neo-Hookean elasticity model without volume change. The expression of the heat power density $\mathrm{s}_{\text {ent }}$ due to entropic coupling changes as a function of the considered model.

Note that the elasticity of real rubber actually features both types of thermoelastic coupling, but entropic coupling is preponderant (the isentropic type is only visible at low strains, before so-called thermoelastic inversion) [50, 51]. The applicability of TSA to rubber at low strains has been discussed in Ref. [52]. As a general remark, classical thermographic approaches to studying thermoelasticity, plasticity, fatigue and plasticity [53-58] are not directly applicable to rubber-like materials today.

\section{Materials and Methods}

Figure 1 shows the experimental set-up. Two-dimensional "composite" granular samples were prepared using cylinders made of two types of materials: thermoplastic polyurethane (TPU) and polyoxymethylene (POM). The TPU was a commercial grade (UR3558, Axson Technologies) composed of isocyanate (100 parts in weight) and polyol (42 parts in weight). It was molded at ambient temperature in cylindrical holes by PCM Technologies S.A.S. (France). The POM was directly bought in the form of cylinders made of black porosity-free unfilled acetal copolymer. TPU and POM feature different responses in terms of stiffness and thermoelastic coupling. POM is much more rigid than TPU (tensile elastic modulus ratio of about 700). In terms of thermoelastic coupling, within the range of mechanical loading considered for the study at ambient temperature, POM is governed by isentropic coupling [34-36] while TPU is governed by entropic coupling [59, 60]. The material density and specific heat of TPU at $20{ }^{\circ} \mathrm{C}$ were equal to $1040 \mathrm{~kg} / \mathrm{m}^{3}$ and $1470 \mathrm{~J} /(\mathrm{kg} . \mathrm{K})$, respectively. The POM cylinders were similar to those used in our previous studies [34-36]: density of $1420 \mathrm{~kg} / \mathrm{m}^{3}$, specific heat of $1460 \mathrm{~J} /$ (kg.K). The thermal diffusivities of TPU and POM were estimated at $0.13 \mathrm{E}-6 \mathrm{~m}^{2} / \mathrm{s}$ and $0.16 \mathrm{E}-6 \mathrm{~m}^{2} / \mathrm{s}$ respectively.

In order to obtain a "bidisperse" granular configuration, the diameters of the POM and TPU cylinders were different, equal to $10.5 \mathrm{~mm}$ and $12.0 \mathrm{~mm}$ respectively. Cylinder height was equal to $60 \mathrm{~mm}$. One of the two circular faces of each cylinder was polished to have a smooth surface. Cylinders were randomly placed in parallel in a rectangular steel frame. The surface of the cylinder network was painted a matte black color to maximize thermal emissivity (0.96), see Fig. 1-a. In

(a)
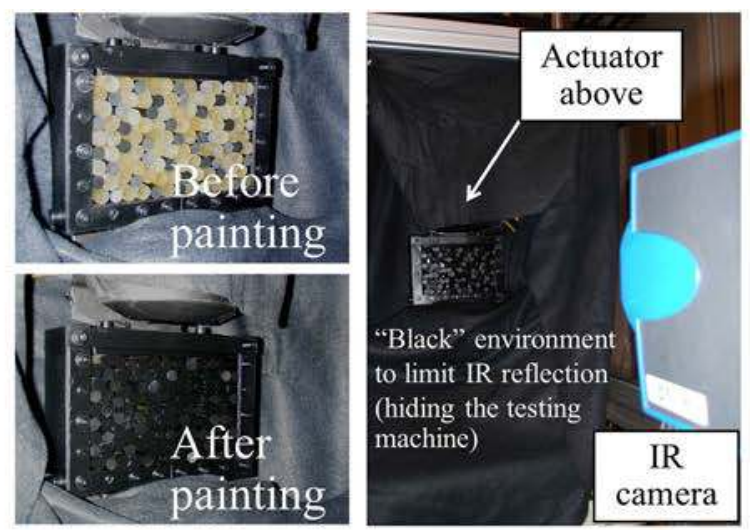

(b)

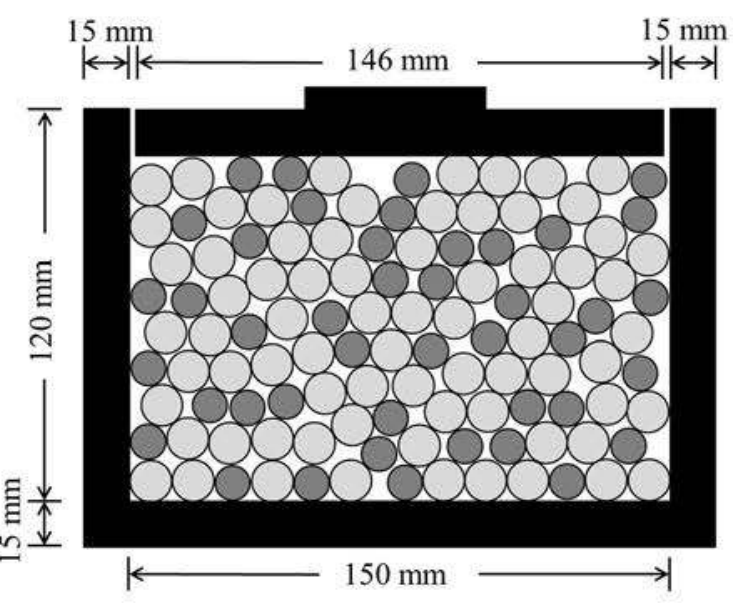

(c)

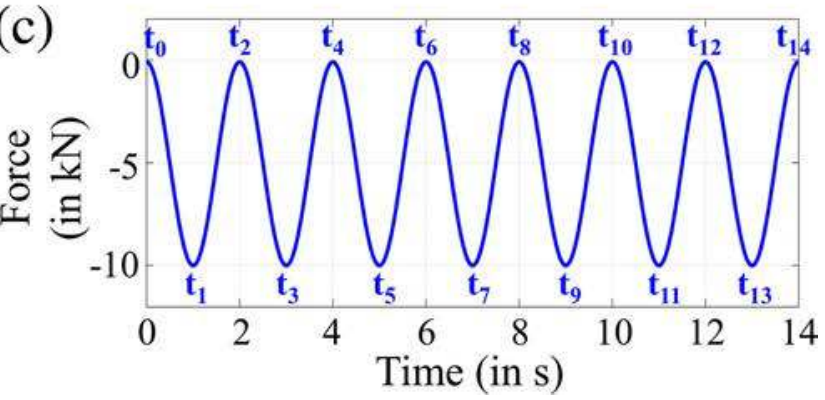

Fig. 1 Experimental set-up: a) photos of the device, b) schematic view of a tested granular sample. TPU and POM cylinders are represented in light and dark grey, respectively, c) mechanical loading 
Fig. 2 Displacements of the cylinder centers: a) from 0 to -0.1 $\mathrm{kN}$, b) from 0 to $-10 \mathrm{kN}$. The vector lengths are proportional to the displacement magnitude
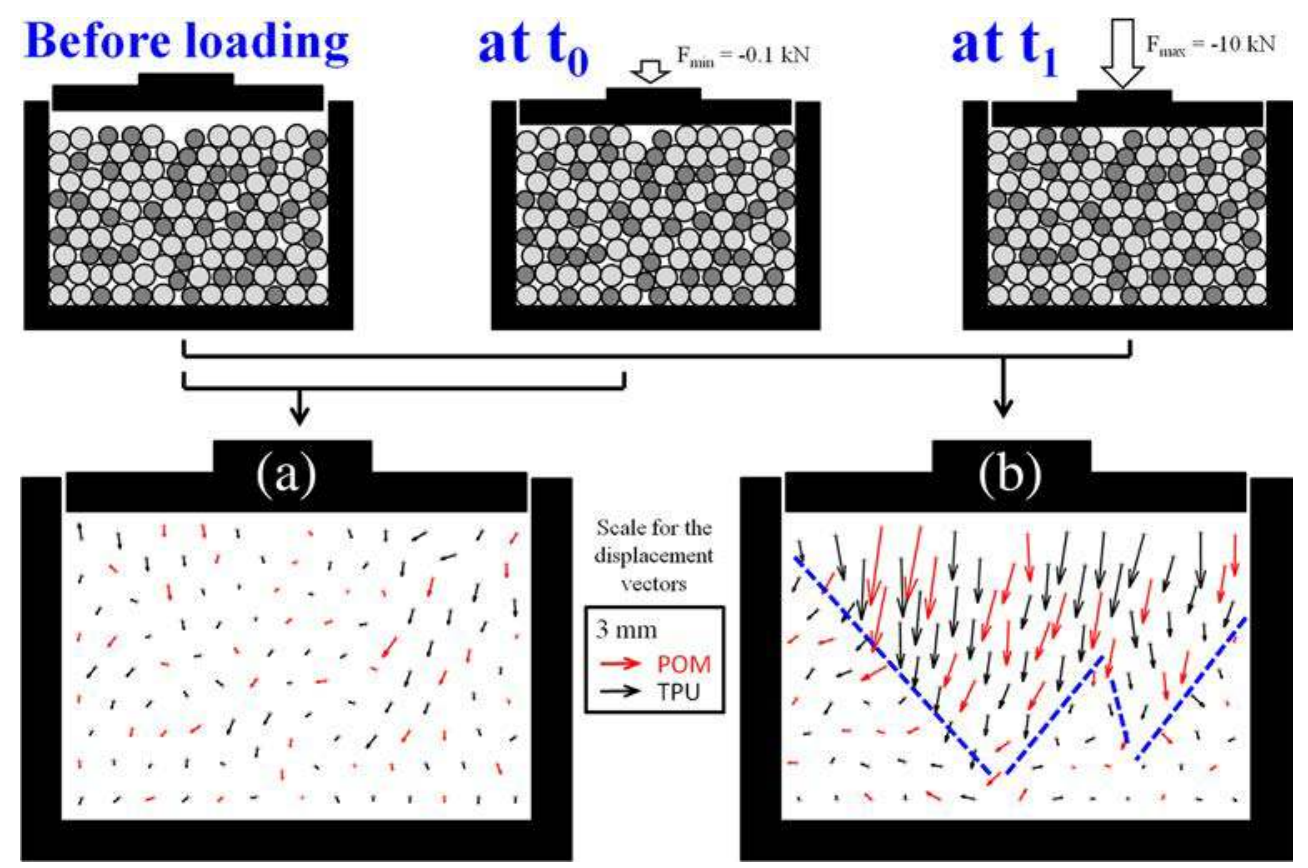

addition, the immediate environment was surrounded with black boards and curtains to limit reflections in the infrared range. The configuration in Fig. 1-b, corresponding to the experimental case developed in this paper, had a total of 116 cylinders (43 POM and 73 TPU).

Mechanical loading consisted of a sinusoidal compression force applied to the top of the granular sample using a MTS $\pm 15 \mathrm{kN}$ uniaxial testing machine. The bottom part and the two vertical walls of the metallic frame were fixed, while the upper part moved downwards, leading in practice to a macroscopic confined compression state. Figure 1-c shows the signal applied for the test: 7 cycles, period of $2 \mathrm{~s}$, minimum compression force $F_{\text {min }}$ of $-0.1 \mathrm{kN}$, maximum compression force $F_{\max }$ of $-10 \mathrm{kN}$. In the following, times at the top and bottom of each cycle are denoted $t_{i}$ (with $i$ from 0 to 14, see Fig. 1-c). Before starting the force oscillation at time $t_{0}$, the minimum load $F_{\text {min }}$ was maintained for $20 \mathrm{~min}$ in order to start the test in thermal and mechanical equilibrium. Indeed, the initial compaction of the granular material (application of the minimum compression force $F_{\min }$ for the first time) led to temperature changes, mainly due to friction between particles finding their locations. The duration of $20 \mathrm{~min}$ ensured that the test would start in steady-state configuration (both mechanically and thermally). Tests were performed at ambient temperature $\left(28^{\circ} \mathrm{C}\right)$. A Cedip Jade III-MWIR camera (wavelength range of 3.5$5 \mu \mathrm{m}, 320 \times 240$ pixels, $\mathrm{NETD}^{1}=0.02{ }^{\circ} \mathrm{C}$ ) was employed

\footnotetext{
${ }^{1}$ Temperature measurement resolution can be assimilated with the noise equivalent temperature difference (NETD), which is in general given in the camera supplier datasheet. In the metrological sense, the measurement resolution is defined by the change in quantity being measured that causes a change in the corresponding indication of greater than one standard deviation of the measurement noise [61]. The lower the measurement resolution, the better the quality of the experimental technique.
}

to acquire the temperature fields on the surface of the cylinder network during cyclic loading, with an acquisition frequency of $150 \mathrm{~Hz}$. Note that the usual condition for TSA in terms of frequencies ("the acquisition frequency shall not be a multiple of the loading frequency") is not required for the present analysis of a few mechanical cycles.

\section{Overall Analysis}

This section provides an analysis of the thermal response when the IR camera acquired images of the whole set of particles $(320 \times 240$ pixels covering the entire granular surface). The spatial resolution ${ }^{2}$ of the measured temperature maps was equal to $0.50 \mathrm{~mm}$. The "Local analysis" section will provide an analysis using a better (lower) spatial resolution in specific zones of the granular assembly.

\section{Preliminary Observations}

Before analyzing temperatures, let us observe the displacements of the cylinders (see Fig. 2). Displacement vectors were extracted by temperature map image processing with Matlab, thanks to the strong contrast with the voids, using Circular Hough Transform. The amplitudes of the displacements under the minimum load $(-0.1 \mathrm{kN})$ were of the order of magnitude of $1 \mathrm{~mm}$, and reached more than $5 \mathrm{~mm}$ under the maximum

\footnotetext{
${ }^{2}$ In the metrological sense, the spatial resolution of a full-field technique is defined as the shortest distance between two spatially independent measurements. The lower the spatial resolution, the better the full-field measurement technique. With the IR camera used here, featuring independent sensors, the spatial resolution was equal to the pixel size projected on the observed surface.
} 
load $(-10 \mathrm{kN})$. Triangular zones can be distinguished under the maximum force (see Fig. 2-b). This pattern is typical of a monodisperse granular assembly, as reported in Ref. [35] or in the last figure in Ref. [34]. For the present study dealing with a "composite" assembly, the combination of two different materials and two different diameters led to a monodisperse-like response in terms of particle displacements. Large displacements are clearly observed, much greater than the IR pixel size projected on the observed surface $(0.50 \mathrm{~mm})$. Consequently, a pixel of the IR camera does not "see" the same material point during mechanical loading. This situation prevents temperature difference maps from being easily determined and has therefore to be taken into account when processing the thermal images.

\section{Analysis of Irreversible Phenomena}

The analysis performed in the present section is based on the assumption that the (reversible) thermoelastic response is null over a mechanical cycle: the cyclically produced/absorbed heat due to thermoelastic couplings is null over a cycle. On the contrary, the heat due to mechanical irreversibility is always positive. This heat produced by mechanical irreversibility is usually named mechanical dissipation or intrinsic dissipation [62-64]. For granular materials, irreversibility can be related to friction at the particle contacts, as well as to mechanical phenomena inside the matter itself, in particular in the stress concentration zones. For polymer materials, mechanical irreversibility may be related to viscosity and damage (fatigue, cavitation, micro-crack initiation and growth). As the thermoelastic calorific response is null over a mechanical cycle, the effect of mechanical dissipation can be detected by temperature map differences between entire numbers of cycles. Despite the problem of large displacements mentioned in the "Preliminary observations" section, the processing here is simple because the granular assembly is expected to return to almost the same geometric configuration at each mechanical cycle. Temperature changes due to irreversibility can be then detected by image subtraction. For instance, Fig. 3-a shows the temperature differences between times $t_{3}$ and $t_{5}$ (corresponding to one mechanical cycle, see Fig. 1-c). It can be observed that the values are close to zero except at some contact zones between particles. In particular, strong thermal activity is located along the two inclined lines of the triangular zone mentioned in the "Preliminary observations" section (compare with Fig. 2-b). The same processing was performed between times $t_{3}$ and $t_{9}$, i.e. for three mechanical cycles. The results are shown in Fig. 3-b. The temperature differences observed are higher than previously, which can be explained by the localized accumulation of the mechanical dissipation over the three cycles. Other configurations were tested using different numbers of cycles, demonstrating the ability of the methodology to detect localized mechanical dissipation at the particle contacts (see also below for an analysis at a better spatial resolution). As a general remark, the higher the number of mechanical cycles, the better the visualization of mechanical dissipation effect. Indeed, heat due to irreversibility accumulates over the cycles, contrary to the heat due to thermoelastic couplings which cancels at each cycle. However, it can be noted that a single cycle is sufficient to detect the calorific signature of interparticle friction.

\section{Analysis of Thermoelastic Couplings}

The heat due to thermoelastic couplings for each loading and unloading stage is equal in norm but with opposite signs, and can be revealed by considering a half-cycle. However, the image processing is tricky because of the large displacements of the particles, as explained in the "Preliminary observations" section. In the present case, only the first half-cycle (compression, from $t_{0}$ to $t_{1}$ in Fig. 1-c) is used. Indeed, the initial
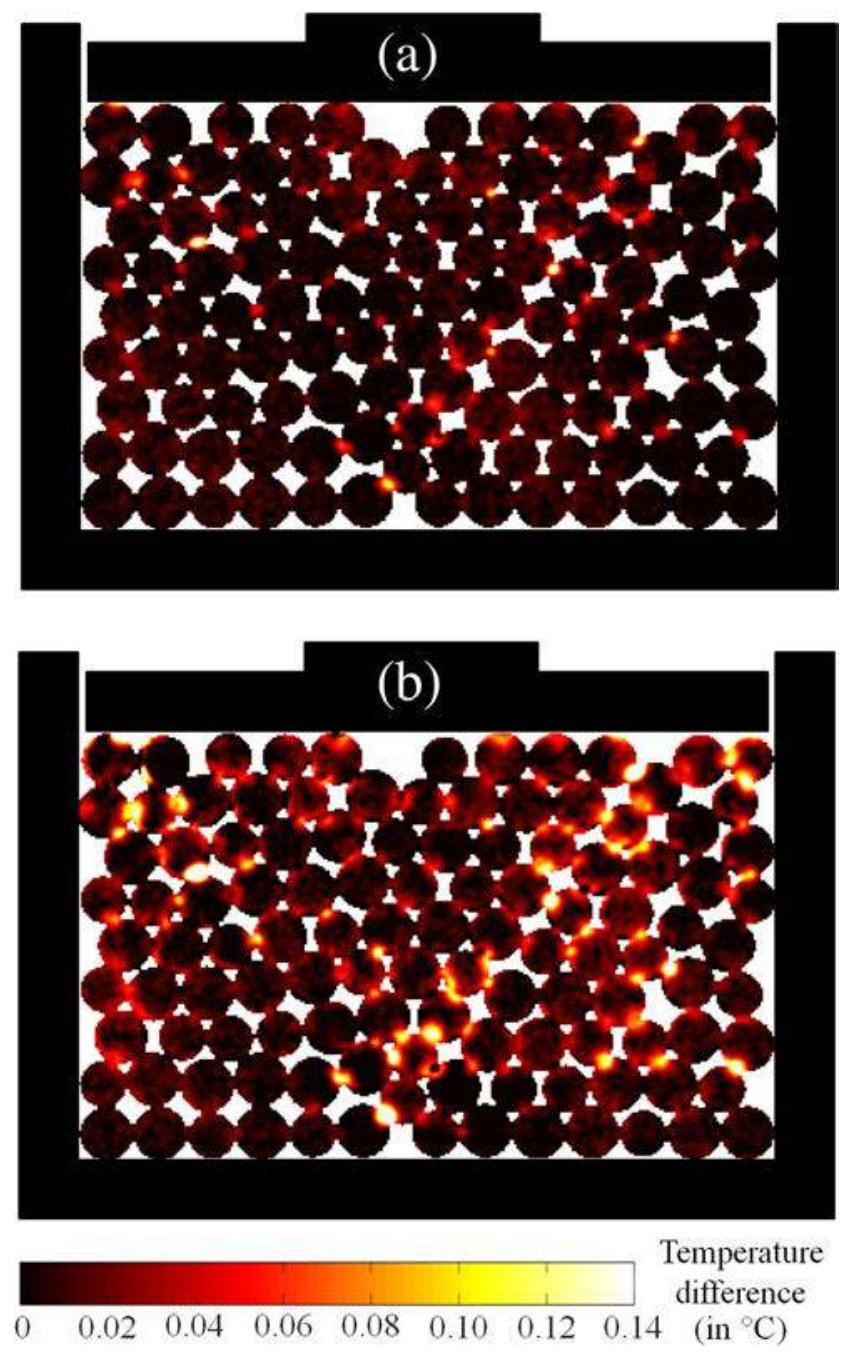

Fig. 3 Thermal signature of irreversible phenomena: map of temperature differences a) for one mechanical cycle from times $t_{3}$ to $t_{5}, \mathrm{~b}$ ) for three mechanical cycles from times $t_{3}$ to $t_{9}$ 


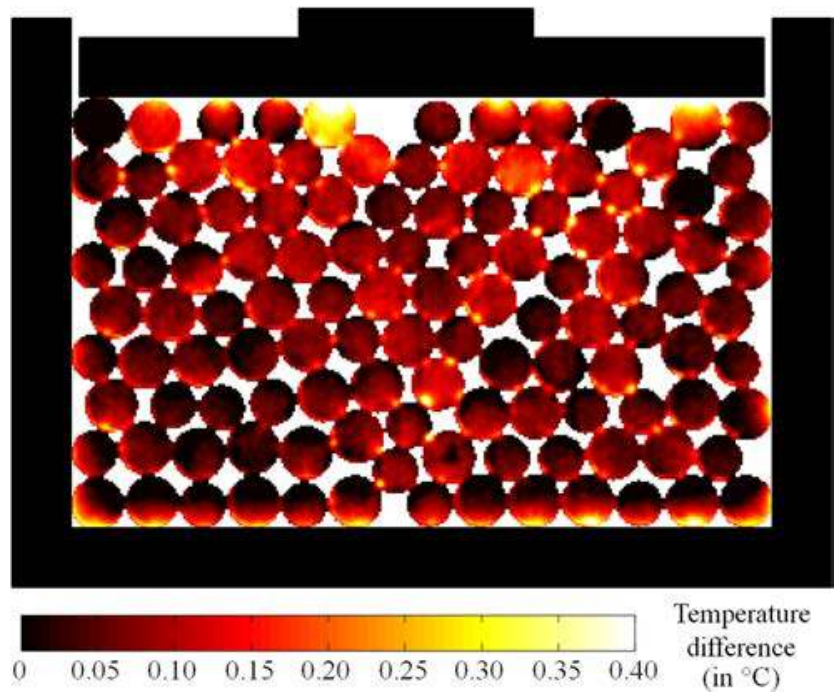

Fig. 4 Thermal signature of thermoelastic couplings: map of temperature differences over a half-cycle, between times $t_{0}$ and $t_{1}$

temperature map at $t_{0}$ is homogeneous, simplifying the calculation of the temperature changes (subtraction of a constant value). Figure 4 shows the map of temperature differences due to thermoelastic couplings which was obtained from $t_{0}$ to $t_{1}$. Values are greater than those in Fig. 3, obtained over three entire cycles: max. $0.40{ }^{\circ} \mathrm{C}$ for a half-cycle (Fig. 4) compared with max. $0.14{ }^{\circ} \mathrm{C}$ accumulated over three cycles (Fig. 3-b). This shows that, over a half-cycle, the thermoelastic effects are much greater than the irreversible effects. It can also be noted that heating is not visualized only at the contacts; it is also distributed inside the particles. Hotter particles are mainly located within the triangular zone identified in "Preliminary observations" section (compare with Fig. 2-b) and are mainly comprised of TPU. This latter observation shows that entropic coupling (evinced by TPU) is stronger than isentropic coupling (evinced by POM). However, further analysis requires a better spatial resolution of the temperature maps, as presented in the next section.

\section{Local Analysis}

Complementary results were obtained using a better (smaller) spatial resolution. In practice, measurements were performed after bringing the IR camera closer to the granular sample. The spatial resolution of the temperature maps was equal to $0.143 \mathrm{~mm}$. Other test conditions were similar to those considered in "Overall analysis" section.

\section{Analysis of irreversible phenomena (over entire numbers of cycles)}

Figure 5-a shows the zone of interest, which was chosen at the bottom edge of the triangular zone where strong activity was observed in Fig. 3-b. Similarly to the overall analysis, Fig. 5-c
Fig. 5 Thermal signature of irreversible phenomena at a local scale: a) location of the zone of interest, b) temperature change from time $t_{0}$ at five contact points for each mechanical cycle, c) map of temperature differences for one cycle from $t_{3}$ to $t_{5}$, d) same for three mechanical cycles from $t_{3}$ to $t_{9}$
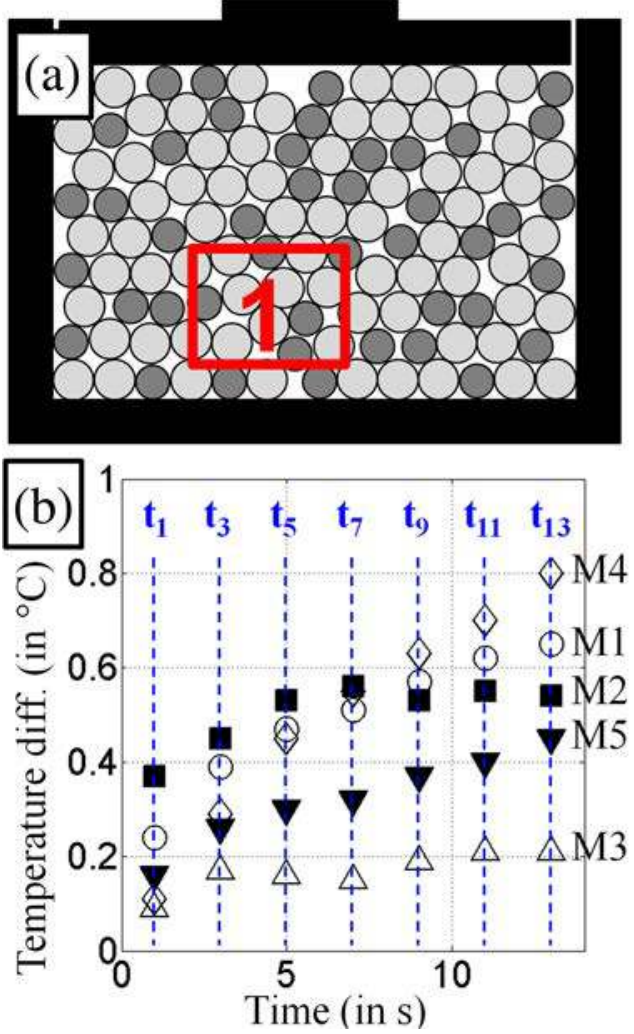

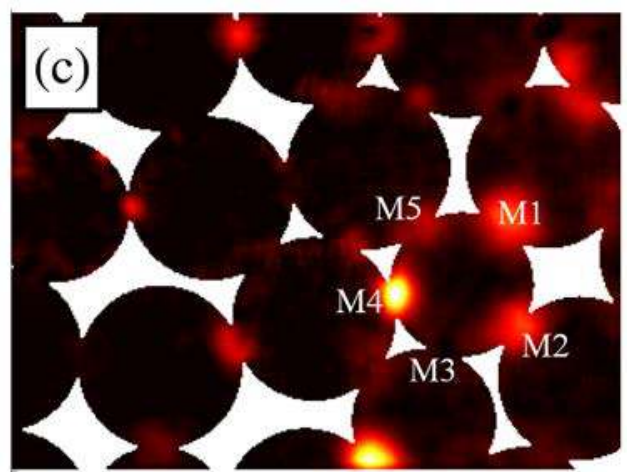

Temperature
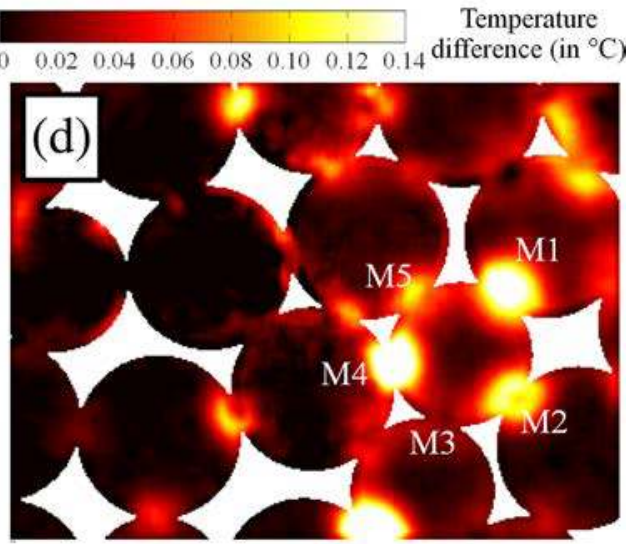
and - $\mathrm{d}$ show the temperature differences from $t_{3}$ to $t_{5}$ (one mechanical cycle) and from $t_{3}$ to $t_{9}$ (three mechanical cycles), respectively. The better spatial resolution enables us to clearly highlight hot zones on both sides of the contact zones. As the thermal diffusivities of the two constitutive materials are close $\left(0.16 \mathrm{E}-6 \mathrm{~m}^{2} / \mathrm{s}\right.$ for POM and $0.13 \mathrm{E}-6 \mathrm{~m}^{2} / \mathrm{s}$ for TPU), it can be assumed that the zones of highest thermal activity mainly resulted from friction and symmetric heat diffusion on both sides of each contact zone, rather than from mechanical dissipation inside the materials. This latter possibility would have led to a very different thermal activity field on each side of POM-TPU contacts. However, it cannot be excluded that viscosity or damage occurred in the stress concentration zones, contributing to mechanical dissipation. A heat source reconstruction [65] will be performed in future works to quantity potential mechanical dissipation inside the matter. Let us note that, the thermal diffusivities of the two constitutive materials being low (compared to metallic materials, for instance), heat diffusion has a weak influence on the results at the macroscopic scale as described in the "Overall analysis" section. Figure 5-b shows the temperature change at each cycle measured from the beginning of the test (time $t_{0}$ ) at five contacts around a particle. Values progressively increase, as expected because of the accumulation of mechanical dissipation by friction over the cycles. It can be noted that the temperature change at point M2 stabilized from time $t_{7}$. This can be explained by a change in the friction conditions at this point, leading to an anticipated equilibrium between heat production (mechanical dissipation due to friction) and heat loss (by conduction and convection).

\section{Analysis within a Mechanical Cycle}

Figure 6-a shows the temperature difference map between times $t_{0}$ and $t_{1}$ (half-cycle), as in the "Analysis of thermoelastic couplings" section for the overall analysis. Temperature patterns are different from those observed for the analysis of the irreversible phenomena. This is not surprising, because the thermoelastic effect depends on the material type (POM or TPU) whereas the mechanical dissipation due to friction depends on the pair of materials considered. The spatial resolution attained enables us to distinguish differences between the two sides of each contact zone. For instance, Fig. 6-b and -c shows the temperature changes over the entire cycle for two pairs of material points, each one being on one side of a contact zone. For points $\mathrm{P} 1$ and $\mathrm{P} 2$ located in TPU, the temperature increased from times $t_{0}$ to $t_{1}$ then decreased from $t_{1}$ to $t_{2}$, in agreement with a thermoelastic response governed by entropic coupling; heat was produced then reabsorbed. A small temperature increase is observed at the end of the cycle: this is the signature of the mechanical dissipation produced by friction during the cycle. For points P3 and P4 located in POM, temperatures slightly increased over the whole duration of the cycle. Isentropic coupling in POM is actually
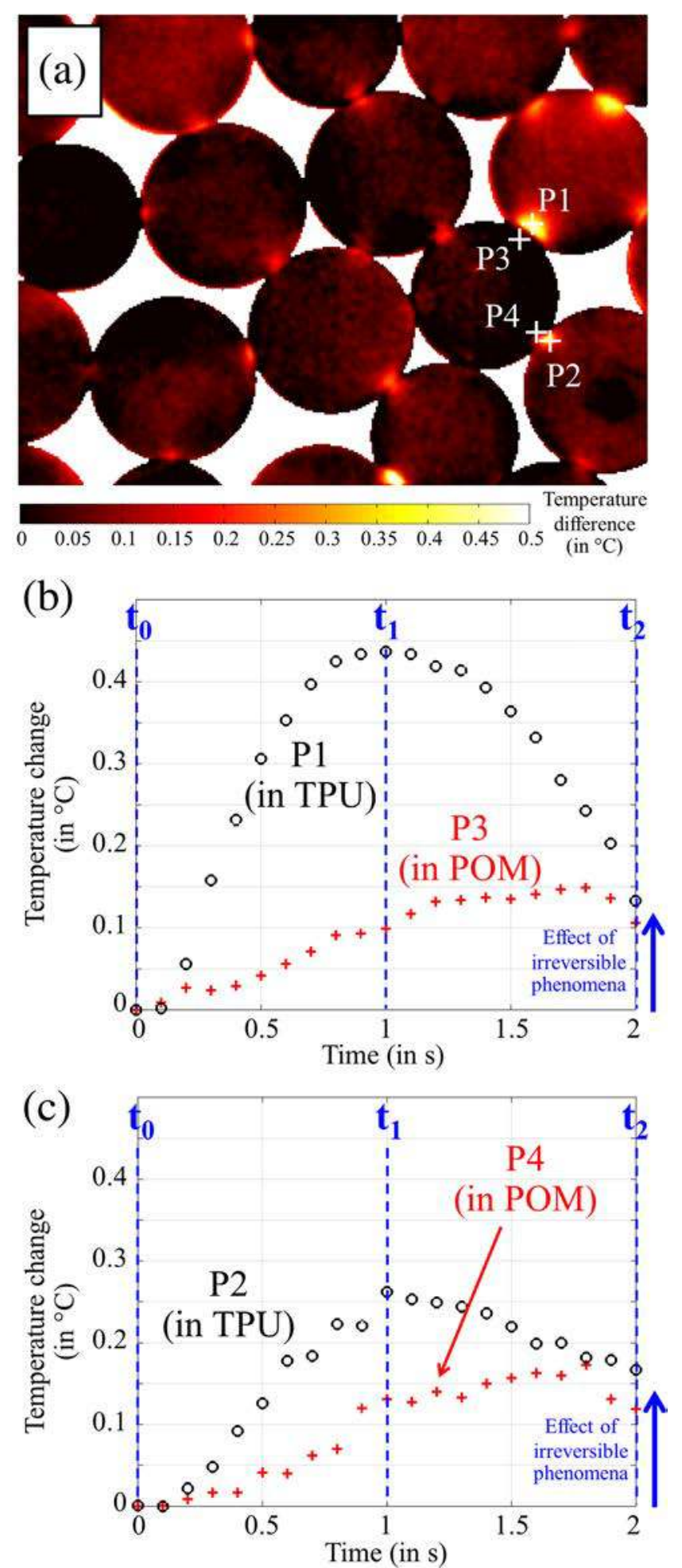

Fig. 6 Results at a local scale within a mechanical cycle: a) map of temperature differences over a half-cycle, between times $t_{0}$ and $t_{1}, \mathbf{b}$ ) temperature change at points $\mathrm{P} 1$ and $\mathrm{P} 3$ over a full cycle, between $t_{0}$ and $\left.t_{2}, \mathbf{c}\right)$ same for points $\mathrm{P} 2$ and $\mathrm{P} 4$

negligible compared to the mechanical dissipation caused by friction. Note that points $\mathrm{P} 1$ and $\mathrm{P} 2$ reached nearly the same temperature at the end of the cycle, confirming the visualization 
Fig. 7 Thermal signatures of irreversible phenomena and thermoelastic couplings in two zones of the granular assembly

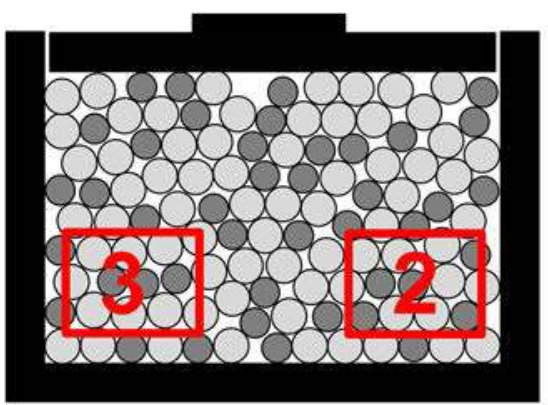

Irreversible phenomena evidenced over three mechanical cycles

Thermomechanical couplings evidenced over a half-cycle

Maps in ${ }^{\circ} \mathrm{C}$

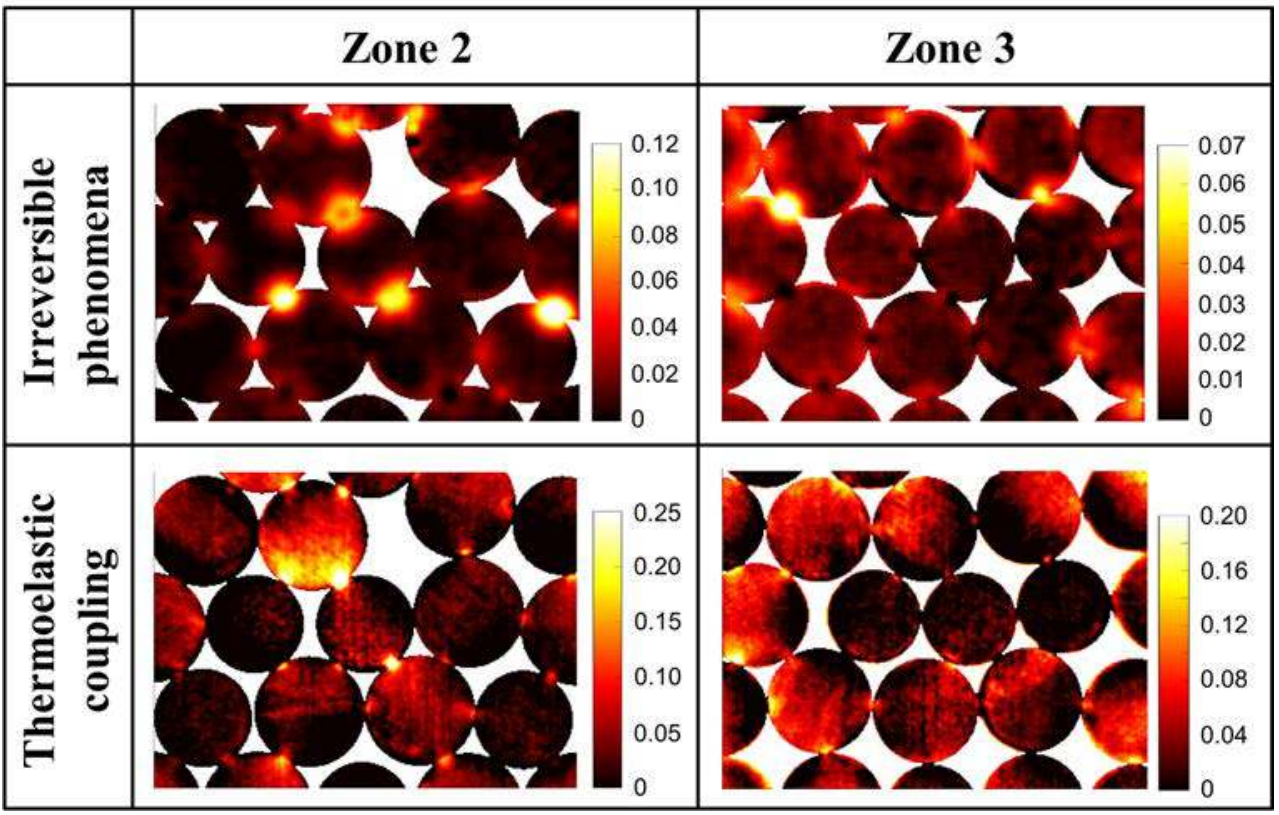

of solely mechanical dissipation effect at the end of the cycle. The same comments can be made for points $\mathrm{P} 3$ and $\mathrm{P} 4$.

Finally, Fig. 7 presents additional maps obtained for two other zones in the granular assembly. They are located in zones of low thermal activity compared to Zone 1 (see Fig. 3). For both zones, processing was performed to reveal irreversible phenomena and thermoelastic couplings. Each map has its own color scale in order to better see its specific range of values. Although the values are much lower than for Zone 1, the two types of thermal signature are clearly identified. It is worth noting that the method clearly distinguishes the two types of phenomenon. As an example, it is possible to reveal contact zones with low mechanical dissipation effect (low friction) and strong thermoelastic couplings (high normal force), or the contrary. Other tests were performed using other distributions of TPU and POM cylinders in the frame, confirming the ability of the methodology to reveal the two types of thermal signature.

\section{Conclusion}

Over the last few decades, several experimental techniques have been developed for the full-field mechanical analysis of granular media. In particular, photoelasticimetry is a relevant method for the measurement of shear stresses in particles made of birefringent transparent materials. For the analysis of thermomechanical phenomena, infrared thermography is in principle applicable to any type of material, but its application to the study of granular samples remains complicated. The present study provides arguments for the choice of relevant constitutive materials for such analyses, in terms of the thermoelastic coupling to be featured by these materials. Confined compression tests were performed on a granular sample comprised of both entropic and isentropic elastic materials. Thermoelastic coupling and interparticle friction were separately evidenced, providing two distinct aspects of the thermomechanical analysis of granular materials from thermal measurements. In particular, a strong thermal response was observed in the stress concentration areas of the TPU cylinders in the contact zones. Previous studies performed with only isentropic materials [34-36] afforded us an analysis within the Thermoelastic Stress Analysis framework, but the methodology required restrictive loading conditions (high loading frequency and numerous mechanical cycles for the processing). It is worth noting that the loading signal applied in the present study does not require a specific testing machine in 
terms of loading frequency, such as a fatigue machine. Moreover, only a few mechanical cycles are necessary for the analysis: a half-cycle for thermoelastic coupling, and one cycle minimum for irreversible phenomena. It can thus be claimed that infrared thermography provides two distinct routes for the analysis of granular materials by distinguishing the reversible and irreversible parts from the global thermomechanical response. In particular, rubber-like entropic particles (such as TPU) provide strong thermo-elastic responses that could be used to identify the force transfer. More generally, the study opens prospects for the experimental analysis of "soft" granular materials, a topic which is almost completely unexplored [6].

Acknowledgements The authors gratefully acknowledge the company PCM Technologies S.A.S., Champtocé-sur-Loire, France, for its support during this research. The authors also gratefully acknowledge the Ministère de l'Europe et des Affaires Etrangères (MEAE) and the Ministère de l'Enseignement supérieur, de la Recherche et de l'Innovation (MESRI) in France, as well as the Office of the Higher Education Commission (OHEC) of the Ministry of Education in Thailand. The authors also gratefully acknowledge the French Embassy in Thailand and Campus France for their support during this research (PHC SIAM 2018, Project 40710SE). The authors would also like to acknowledge the finanacial support through the Research Grant for New Scholar (MRG6080251) from the Thailand Research Fund (TRF) and Thailand's Office of the Higher Education Commission (OHEC).

\section{References}

1. Jaeger HM (2005) Sand, jams and jets. Phys World 18:34-39

2. Jaeger HM, Nagel SR, Behringer RP (1996) Granular solids, liquids, and gases. Rev Mod Phys 68:1259-1273

3. Casagrande A, Carillo N (1944) Shear failure of anisotropic materials. J Boston Soc Civil Eng 31:74-87

4. Dantu $\mathrm{P}$ (1957) Contribution à l'étude mécanique et géométrique des milieux pulvérulents. In: Proceedings of the 4th international conference on soil mechanics and foundation engineering. Butterworth, London, pp 144-148

5. Rowe PW (1962) The stress-dilatancy relation for static equilibrium of an assembly of particles in contact. Proc Roy Soc Lond A Math Phys Sci 269:500-527

6. Radjai F, Roux JN, Daouadji A (2017) Modeling granular materials: century-long research across scales. J Eng Mech 143: 04017002

7. Wolf H, Konig D, Triantafyllidis T (2003) Experimental investigation of shear band patterns in granular material. J Struct Geol 25: 1229-1240

8. Hall SA, Bornert M, Desrues J et al (2010) Discrete and continuum analysis of localised deformation in sand using X-ray $\mu \mathrm{CT}$ and volumetric digital image correlation. Geotechnique 60:315-322

9. Hu Z, Du Y, Luo H et al (2014) Internal deformation measurement and force chain characterization of mason sand under confined compression using incremental digital volume correlation. Exp Mech 54:1575-1586

10. Khalili MH, Brisard S, Bornert M et al (2017) Discrete digital projections correlation: a reconstruction-free method to quantify local kinematics in granular media by X-ray tomography. Exp Mech 57:819-830
11. Park H, Chen W (2012) Two orthogonal layers of metal medium in granular materials for 3D speckle shadowgraph by flash X-ray. Exp Mech 52:1173-1177

12. Nakagawa M, Altobelli SA, Caprihan A et al (1993) Non-invasive measurements of granular flows by magnetic resonance imaging. Exp Fluids 16:54-60

13. Sanfratello L, Fukushima E, Behringer RP (2009) Using MR elastography to image the 3D force chain structure of a quasistatic granular assembly. Granul Matter 11:1-6

14. Hill KM, Fan Y, Zhang J et al (2010) Granular segregation studies for the development of a radar-based three-dimensional sensing system. Granul Matter 12:201-207

15. Parker DJ, Dijkstra AE, Martin TW, Seville JPK (1997) Positron emission particle tracking studies of spherical particle motion in rotating drums. Chem Eng Sci 52:2011-2022

16. Mueth DM, Jaeger HM, Nagel SR (1998) Force distribution in a granular medium. Phys Rev E 57:3164-3169

17. Slominski C, Niedostatkiewicz M, Tejchman J (2007) Application of particle image velocimetry (PIV) for deformation measurement during granular silo flow. Powder Techn 173:1-18

18. Hall SA, Wood DM, Ibraim E, Viggiani G (2010) Localised deformation patterning in 2D granular materials revealed by digital image correlation. Granul Matter 12:1-14

19. Richefeu V, Combe G, Viggiani G (2012) An experimental assessment of displacement fluctuations in a $2 \mathrm{D}$ granular material subjected to shear. Geotechnique Lett 2:113-118

20. Shukla A, Damania C (1987) Experimental investigation of wave velocity and dynamic contact stresses in an assembly of disks. Exp Mech 27:268-281

21. Roessig KM, Foster JC, Bardenhagen SG (2002) Dynamic stress chain formation in a two-dimensional particle bed. Exp Mech 42: 329-337

22. Zhang J, Majmudar TS, Sperl M, Behringer RP (2010) Jamming for a 2D granular material. Soft Matter 6:2982-2991

23. Bigoni D, Noselli G (2010) Localized stress percolation through dry masonry walls. Part I-experiments. Eur J Mech A-Solids 29: 291-298

24. Zhang J, Majmudar TS, Tordesillas A, Behringer RP (2010) Statistical properties of a 2D granular material subjected to cyclic shear. Granul Matter 12:159-172

25. Wood DM, Lesniewska D (2011) Stresses in granular materials. Granul Matter 13:395-415

26. Lesniewska D, Wood DM (2011) Photoelastic and photographic study of a granular material. Geotechnique 61:605-611

27. Guo P (2012) Critical length of force chains and shear band thickness in dense granular materials. Acta Geotech 7:41-55

28. Estep J, Dufek J (2012) Substrate effects from force chain dynamics in dense granular flows. J Geophys Res Earth Surf 117:F01028

29. Zhang L, Cai S, Hu Z, Zhang J (2014) A comparison between bridges and force-chains in photoelastic disk packing. Soft Matter 10:109-114

30. Coulais C, Behringer RP, Dauchot O (2014) How the ideal jamming point illuminates the world of granular media. Soft Matter 10: 1519-1536

31. Mirbagheri SA, Ceniceros E, Jabbarzadeh M et al (2015) Sensitively photoelastic biocompatible gelatin spheres for investigation of locomotion in granular media. Exp Mech 55:427-438

32. Luong MP (1986) Characteristic threshold and infrared vibrothermography of sand. Geotech Testing J 9:80-86

33. Luong MP (2007) Introducing infrared thermography in soil dynamics. Infrared Phys Techn 49:306-311

34. Chaiamarit C, Balandraud X, Preechawuttipong I, Grédiac M (2015) Stress network analysis of 2D non-cohesive polydisperse granular materials using infrared thermography. Exp Mech 39: 761-769 
35. Jongchansitto P, Balandraud X, Grédiac M et al (2014) Using infrared thermography to study hydrostatic stress networks in granular materials. Soft Matter 10:8603-8607

36. Jongchansitto P, Preechawuttipong I, Balandraud X, Grédiac M (2017) Numerical investigation of the influence of particle size and particle number ratios on texture and force transmission in binary granular composites. Powder Techn 308:324-333

37. Schneebeli G (1956) Une analogie mécanique pour les terres sans cohésion. C R Hebd. Acad Sci 243:125-126

38. Dulieu-Barton JM, Stanley P (1998) Development and application of thermoelastic stress analysis. J Strain Anal Eng Des 33:93-104

39. Pitarresi G, Patterson EA (2003) A review of the general theory of thermoelastic stress analysis. J Strain Anal Eng Des 38:405-417

40. Greene RJ, Patterson EA, Rowlands RE (2008) Thermoelastic stress analysis. In: Sharpe WN (ed) Springer handbook of experimental solid mechanics. Springer, New York, pp 743-768

41. Chrysochoos A, Dupre JC (1991) Experimental analysis of thermomechanical coupling by infra-red thermography. In: Boehler JP, Khan JP (eds) Anisotropy and localization of plastic deformation. Springer, Dordrecht, pp 540-543

42. Holzapfel GA (2000) Nonlinear solid mechanics: a continuum approach for engineering. Wiley. England, West Sussex, p 310

43. Gough J (1805) A description of a property of caoutchouc or Indian rubber; with some reflections on the cause of the elasticity of this substance. Proc Lit Phil Soc 1:288-295

44. Joule JP (1857) Investigations on rubber. Phil Mag 14:227

45. Meyer KH, Ferri C (1935) Sur l'élasticité du caoutchouc. Helv Chim Acta 18:570-589

46. Verron E, Andriyana A (2008) Definition of a new predictor for multiaxial fatigue crack nucleation in rubber. J Mech Phys Solids $56: 417-443$

47. Baaser H, Hopmann C, Schobel A (2013) Reformulation of strain invariants at incompressibility. Arch Appl Mech 83:273-280

48. Treloar LRG (1943) The elasticity of a network of long chain molecules (I and II). Trans Faraday Soc 39:36-41 241-246

49. Le Cam JB (2010) A review of volume changes in rubber: the effect of stretching. Rubber Chem Techn 83: 247-269

50. Treloar LRG (1973) The elasticity and related properties of rubbers. Rep Prog Phys 36:755-826

51. Chadwick P (1974) Thermo-mechanics of rubberlike materials. Phil Trans R Soc Lond A 276:371-403

52. Hussain AK, Greene RJ, Tomlinson RA (2008) The viability of using thermoelastic stress analysis on rubber at small strain. In: Society for Experimental Mechanics - 11th International Congress and Exhibition on Experimental and Applied Mechanics 2008, June 2-5, 2008 Orlando, Florida, USA, 3, 1237-1244

53. De Finis R, Palumbo D, da Silva MM, Galietti U (2018) Is the temperature plateau of a self-heating test a robust parameter to investigate the fatigue limit of steels with thermography? Fatigue Fracture Eng Mater Struct 41:917-934

54. Enke NF, Sandor BI (1988) Cyclic plasticity analysis by differential infrared thermography. In: Proceding of the VI International Congress on Experimental Mechanics, 830-835

55. Morabito AE, Dattoma V, Galietti U (2002) Energy-analysis of fatigue damage by thermographic technique. In: Proceedings of SPIE-The International Society for Optical Engineering, 4710, 456-463

56. Krapez JK, Pacou D, Gardette G (2000) Lock-in thermography and fatigue limit of metals. Quant Infrared Thermogr 6:277-282

57. De Finis R, Palumbo D, Ancona F, Galietti U (2017) Fatigue behaviour of stainless steels: A multi-parametric approach. In: Conference Proceedings of the Society for Experimental Mechanics Series. Springer. 9, 1-8

58. Palumbo D, De Finis R, Demelio PG, Galietti U (2017) Study of damage evolution in composite materials based on the Thermoelastic phase analysis (TPA) method. Composites Part B: Eng 117: 49-60

59. Mott PH, Giller CB, Fragiadakis D et al (2016) Deformation of polyurea: where does the energy go? Polymer 105:227-233

60. Lachhab A, Robin E, Le Cam JB et al (2017) Thermomechanical analysis of polymeric foams subjected to cyclic loading: Anelasticity, self-heating and strain-induced crystallization. Polymer 126:19-28

61. Chrysochoos A, Surrel Y (2012) Chapter 1: Basics of metrology and introduction to techniques. In: Grediac M, Hild F Full-field measurements and identification in solid mechanics, Wiley-ISTE, 1-29

62. Halphen B, Nguyen QS (1975) Sur les matériaux standard généralisés. J Mecanique 14:39-63

63. Samaca Martinez JR, Le Cam JB, Balandraud X et al (2013) Mechanisms of deformation in crystallizable natural rubber. Part 1: thermal characterization. Polymer 54:2717-2726

64. Le Cam JB, Samaca Martinez JR, Balandraud X et al (2015) Thermomechanical analysis of the singular behavior of rubber: entropic elasticity, reinforcement by fillers, strain-induced crystallization and the Mullins effect. Exp Mech 55:771-782

65. Beitone C, Balandraud X, Delpueyo D et al (2017) Heat source reconstruction from noisy temperature fields using a gradient anisotropic diffusion filter. Infrared Phys Techn 80:27-37 